\title{
Edge chipping of brittle materials: effect of side-wall inclination and loading angle
}

\author{
Herzl Chai · Brian R. Lawn
}

Published online: 12 October 2007

(C) Springer Science+Business Media B.V. 2007

Erratum to: Int J Fract 145(2):159-165 (2007) DOI 10.1007/s10704-007-9113-2

Due to an unfortunate turn of events this article has been published with an erroneous version of Figure 3. Please find on the following page the correct Figure 3 that should be regarded by the reader as the final version.

The online version of the original article can be found under doi:10.1007/s10704-007-9113-2.

H. Chai

School of Mechanical Engineering, Faculty of Engineering, Tel Aviv University, Tel Aviv, Israel

B. R. Lawn $(\varangle)$

Materials Science and Engineering Laboratory, National Institute of Standards and Technology, Gaithersburg, MD, 20899-8520 USA

e-mail: brian.lawn@nist.gov 
Fig. 3 Side views of Vickers cracks for normal loading $(\phi=0)$ on glass blocks with inclined side faces: (a) $\theta=-20^{\circ}$, $h=0.8 \mathrm{~mm}$; (b) $\theta=+20^{\circ}$, $h=1.0 \mathrm{~mm}$; (c) $\theta=+50^{\circ}$, $h=2.2 \mathrm{~mm}$
(a) $\theta=-20^{\circ}$

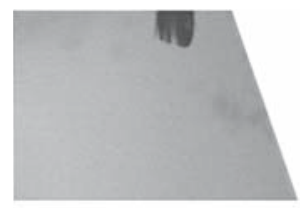

$P=243 \mathrm{~N}$

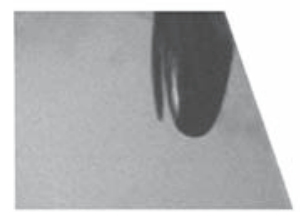

$P=297 \mathrm{~N}$

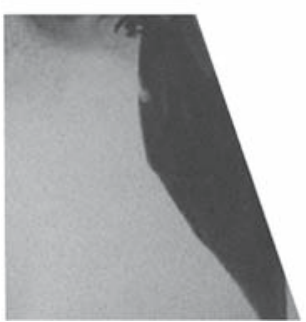

$P=298 \mathrm{~N}$ (b) $\theta=+20^{\circ}$

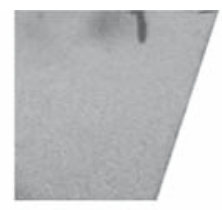

$P=64 \mathrm{~N}$

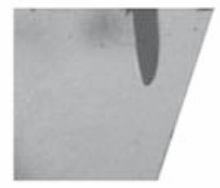

$P=101 \mathrm{~N}$

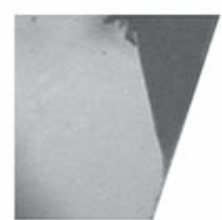

$P=102 \mathrm{~N}$ (c) $\theta=+50^{\circ}$
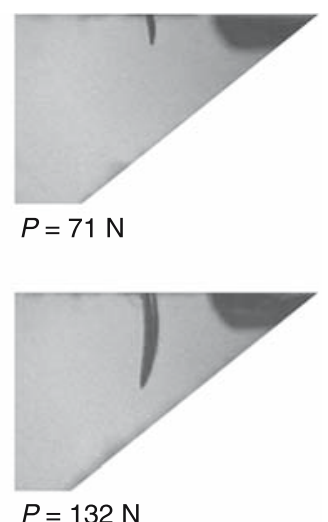

$P=132 \mathrm{~N}$

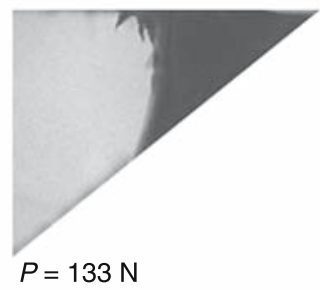

